\title{
A policy brief for congress health care industry \& nursing education
}

\section{Introduction}

A shortage of nursing faculty impacts nursing and health care. With the increased needs of nurses by 2022 there is an urgent need to work to increase the numbers of nurse faculty to educate future nurses. The Nursing Faculty Education Access Program outlines policy options and recommendations to address this need. This brief is written for the congressional health care committee, health care industry and nurse educators for debate on Title VIII funding for nursing education.

\section{Nursing faculty statement of issue}

The aim of this policy brief is to discuss the increased need for more nursing faculty to educate the increased future nursing staffing needs for patient care in regards to the Affordable Care Act and aging population by McMenamin P. ${ }^{1}$

May 2012 Salaries
Nurse Faculty $\$ 68,640$
RNs $\$ 67,930$
Nurse Practitioners $\$ 91,000$
Nurse Anesthetists $\$ 154,400$

There is an increased need for nurse faculty with doctoral education

Nurses pursuing advanced degrees often work as nurse practitioners and anesthetists and receive higher salaries than nurse faculty. Doctoral faculty is needed to prepare the advanced practice nurses (APRNs) as well as baccalaureate nurse generalists (RNs).

\section{Background}

By 2022 an increased employment of 574,400 RNs and APRNs will be needed to keep pace with the demands of nursing

Nurse faculty retirement raises this need to a total of 1.13 million total nurses. ${ }^{1}$ The number of nurses nearing retirement will impact the shortage of nurses and nurse faculty. ${ }^{2}$

\section{Pre-existing policies}

\section{Historically title VIII funds nursing education}

There is a correlation between the rise and fall of this funding and the number of nurses educated in the United States. ${ }^{3}$ The affect of increased funding lasts a decade. "Nursing education has increased over the last century. But inflation has eaten away $74 \%$ of the committed funds". ${ }^{1}$ The health care industry has slowed hiring to only replace nurses. The hospitals are choosing to hire experienced nurses and those with baccalaureate degrees (BSNs). Older nurses have delayed retirement due to the downturn of the economy from 2008.

\author{
Volume I Issue I - 2016 \\ Penny Kessler \\ School of Nursing, University of Minnesota, USA
}

Correspondence: Penny Kessler, Department of School of Nursing, University of Minnesota, USA,

Email kess1056@umn.edu

Received: August 08, 2016 | Published: August 18, 2016

The health care coverage from the Affordable Care Act and aging of Baby Boomers using Medicare will increase the numbers of patients and therefore nurses needed. ${ }^{1}$ All of these policies come together to lead to a critical shortage of nurse faculty and nurses.

\section{Policy options}

\section{Nursing education needs to focus on hiring more nursing faculty to prepare future nurses}

Hiring of nurse faculty is hindered by a shortage of qualified faculty. ${ }^{1}$ Nursing education should introduce and expand the nurse faculty role in doctoral education. Expansion of bridge programs to ease the transition of BSN to doctoral degrees would expand the number of younger nurses interested in a nursing faculty role. Faculty pay should be increased to be more in step with other APRNs to help attract nurses to the nurse faculty role. Lastly, media attention should promote the valuable role of nursing faculty to nursing and healthcare.

\section{Advantages and disadvantages of the options}

\section{One con of each of the policy options is funding}

Who will pay for the options? The alternative to adopt the options is a downward trend in health care. The pro of each of the policy options is maintaining quality health care and safety beyond 2022 .

\section{Recommendations}

i. Decrease the costs of education of future nurse faculty.

ii. Increase the hiring of nurse faculty to address future nurse shortages.

iii. Increase financial support for bridge programs to nurse faculty.

iv. Increase nurse faculty pay to attract more faculty.

v. Promote the role of nurse faculty in media.

\section{Rationale for recommendations}

\section{Cost is a major factor in nurses delaying starting their} doctoral degrees

The University of Minnesota (UMN) Doctor of Nursing Practice (DNP) postbaccaluareate degree costs $\$ 899.77$ per credit. This degree 
requires 55-90 credits with BSN or equivalent and 1000 clinical hours. The UMN DNP post-Master of Nursing costs $\$ 893$ per credit. This degree has $35-45$ required credits. The $\mathrm{PhD}$ nursing program requires 60-70 credits, including 20 dissertation credits. ${ }^{4}$ The reduction of the out of pocket cost for doctoral education would enable faculty to obtain their degree. Another major factor in the faculty shortage is the difference in pay with other nurses with doctoral degrees as described in box. ${ }^{5}$

\section{Acknowledgements}

None.

\section{Conflict of interest}

The author declares there is no conflict of interest.

\section{References}

1. McMenamin P. RN retirements-tsunami warning. ANA, Japan: Springer; 2014.

2. US department of labor bureau of labor statistics. Employment projections for 2012-2022; 2013.

3. Auerbach DI, Buerhaus PI, Staiger DO. Registered nurse supply grows faster than projected amid surge in new entrants ages 23-26. Health Affairs. 2011;30(12):2286-2292.

4. One stop. Graduate tuition and fees twin cities campus. University of Minnesota, USA: Springer; 2013. p. 2.

5. University of minnesota. Comparison of $P h D$ and DNP programs and degrees. USA: Springer; 2013. 